\title{
Article \\ QSAR Assessing the Efficiency of Antioxidants in the Termination of Radical-Chain Oxidation Processes of Organic Compounds
}

\author{
Veronika Khairullina *, Irina Safarova, Gulnaz Sharipova, Yuliya Martynova (D) and Anatoly Gerchikov
}

check for

updates

Citation: Khairullina, V.; Safarova, I.; Sharipova, G.; Martynova, Y.; Gerchikov, A. QSAR Assessing the Efficiency of Antioxidants in the Termination of Radical-Chain Oxidation Processes of Organic Compounds. Molecules 2021, 26, 421. https://doi.org/10.3390/ molecules 26020421

Academic Editor: Alla P. Toropova Received: 14 December 2020 Accepted: 9 January 2021

Published: 14 January 2021

Publisher's Note: MDPI stays neutral with regard to jurisdictional clai$\mathrm{ms}$ in published maps and institutional affiliations.

Copyright: (C) 2021 by the authors. Licensee MDPI, Basel, Switzerland. This article is an open access article distributed under the terms and conditions of the Creative Commons Attribution (CC BY) license (https:// creativecommons.org/licenses/by/ $4.0 /)$.
Faculty of Chemistry, Bashkir State University, 450076 Ufa, Russia; safarova-77@mail.ru (I.S.); gulnaz-sharipova@list.ru (G.S.); Martynovayuz@gmail.com (Y.M.); gerchikov@inbox.ru (A.G.) * Correspondence: Veronika1979@yandex.ru; Tel.: +7-963-906-6567

\begin{abstract}
Using the GUSAR 2013 program, the quantitative structure-antioxidant activity relationship has been studied for 74 phenols, aminophenols, aromatic amines and uracils having $\lg k_{7}=0.01-6.65$ (where $k_{7}$ is the rate constant for the reaction of antioxidants with peroxyl radicals generated upon oxidation). Based on the atomic descriptors (Quantitative Neighborhood of Atoms (QNA) and Multilevel Neighborhoods of Atoms (MNA)) and molecular (topological length, topological volume and lipophilicity) descriptors, we have developed 9 statistically significant QSAR consensus models that demonstrate high accuracy in predicting the $\operatorname{lgk}_{7}$ values for the compounds of training sets and appropriately predict $\operatorname{lgk}_{7}$ for the test samples. Moderate predictive power of these models is demonstrated using metrics of two categories: (1) based on the determination coefficients $\left.\mathrm{R}^{2}\left(\mathrm{R}^{2} \mathrm{TSi}_{1}, \mathrm{R}^{2}{ }_{0}, \mathrm{Q}^{2}{ }_{(\mathrm{F} 1}\right), \mathrm{Q}^{2}\left({ }_{\mathrm{F} 2}\right), \overline{\mathrm{R}_{\mathrm{mTSi}}^{2}}\right)$ and based on the concordance correlation coefficient (CCC)); or (2) based on the prediction lgk $\mathrm{k}_{7}$ errors (root mean square error (RMSEP), mean absolute error (MAE) and standard deviation (S.D.)) The RBF-SCR method has been used for selecting the descriptors. Our theoretical prognosis of the $\operatorname{lgk}_{7}$ for 8-PPDA, a known antioxidant, based on the consensus models well agrees with the experimental value measure in the present work. Thus, the algorithms for calculating the descriptors implemented in the GUSAR 2013 program allow simulating kinetic parameters of the reactions underling the liquid-phase oxidation of hydrocarbons.
\end{abstract}

Keywords: antioxidant activity; antioxidants; QSAR models; GUSAR 2013 program; QNA descriptors; MNA descriptors

\section{Introduction}

Currently, the antioxidant properties of natural and synthetic substances are in the focus of chemical, biological, and pharmacological studies. This diversified interest relates to the possible use of these compounds as stabilizers in food, polymer, and fuel industries. Additionally, antioxidants are promising for anticancer and antitumor pharmaceuticals [1-13]. Indeed, antioxidants are able to deactivate both typical radical intermediate products and molecular oxidation products, the excessive formation of which can provoke the appearance and development of various pathologies, including cancer, premature aging, diabetes, etc. [13-20].

As is known, oxidation of organic compounds occurs via the chain mechanism that involves alkyl and peroxyl radicals [14,15]. The accumulated organic hydroperoxides decompose generating radicals, thereby increasing the rate of oxidation. The oxidation can be inhibited by the following three ways:

- Termination of the chains by the reaction of the inhibitor with peroxyl radicals;

- Termination of the chains by the reaction of the inhibitor with alkyl radicals;

- Termination with the compounds inducing the non-radical decomposition of the organic hydroperoxide (only if the latter is the main auto-initiator). 
According to Denisov et al. [14], antioxidants are divided in 7 groups depending on the deactivation regime of oxidation. A detailed analysis of each of them is presented in the Supplementary Materials.

A single criterion for evaluating for assessing the antioxidant activity (AOA) of organic compounds is absent. AOA can be characterized with various semi-quantitative and quantitative parameters. The $\mathrm{IC}_{50}$ concentration is widely used as a semi-quantitative measure of $\mathrm{AOA}\left(\mathrm{IC}_{50}\right.$ relates to the intensity of the oxidation process reduced two times or the amount of malonic dialdehyde formed upon the oxidation of unsaturated fatty acids [21-26]). The reliable quantitative characterization of AOA may be based on the rate constants of the reaction of antioxidant molecule with radicals relaying the oxidation chain. These rate constants are usually designated as $k_{7}$ or $k_{I n}$ in the case of compositions based on different antioxidants. Measuring these kinetic parameters may be performed by known methods of chemical kinetics [14,27].

In the scientific literature, one can find the works on QSAR modeling of antioxidants from the classes of phenols and polyphenols, in which the descriptors were calculated using quantum chemistry methods. In these studies, indicative variables were used jointly with quantum-chemically calculated descriptors (energies of the frontier molecular orbitals $\mathrm{E}_{\mathrm{HOMO}}$ and $\mathrm{E}_{\mathrm{LUMO}}$, difference in the heats of formation of phenol and its radical $\left(\Delta \Delta \mathrm{H}_{\mathrm{R}}\right)$, bond dissociation enthalpies etc.) [28-34]. However, all these works are built on fairly narrow sets of similar compounds, e.g., the effect of para-substituents on the antioxidant activity of 10 and 27 phenol derivatives was studied in works [28] and [29], respectively. Based on quantum chemical calculations, the authors of [28] found that the smaller the BDE number, the higher the antioxidant activity of the modeled compounds. In work [29], using the model reaction of AIBN-induced styrene oxidation $(T=323 \mathrm{~K})$, it was found that the inhibition rate constants $\mathrm{k}_{7}$ for para-substituted phenols correlates with the BrownOkamoto constants $\sigma_{\mathrm{p}}{ }^{+}$. The smaller its numerical value for the para-substituent (i.e., the higher the positive inductive effect of this substituent, the higher the numerical value of $\mathrm{k}_{7}$ ). In the work [30], as a result of modeling 14 para-substituted phenols, 4 QSAR models were built, in which the reducing potency $\left(\mathrm{E}_{\mathrm{mid}}\right)$ correlates with quantum chemical descriptors such as ionization potential of the parent molecule $\left(\mathrm{IP}_{\mathrm{p}}\right)$, spin delocalization of the intermediate radical cation $\left(\mathrm{D}_{\mathrm{s}}{ }^{\mathrm{c}}\right), \mathrm{LUMO}$ of the parent molecule $\left(\mathrm{E}_{\mathrm{LUMOp}}\right)$, difference between the heats of formation of the phenoxyl radical $\left(\Delta \Delta \mathrm{H}_{\mathrm{R}}\right)$ and parent molecule $\left(\Delta \Delta \mathrm{H}_{\mathrm{p}}\right)$. In work [31] it was shown that quantum chemical descriptors such as ionization potentials (IP), absolute electronegativity $(\mathrm{\chi})$, activation energy $\left(\Delta \Delta \mathrm{H}^{\#}\right)$, difference in the heats of formation of compounds and their radicals $\left(\Delta \Delta \mathrm{H}_{\mathrm{R}}\right)$ make a decisive contribution to the antioxidant activity of phenols. The calculation of these descriptors was performed using the AM1 method (MOPAC 6.0 software). In work [32], moderate correlations for 30 Schiff bases were obtained between antiradical activity and quantum chemistry descriptors including the bond dissociation enthalpies related to the first and second hydrogen atom transfer (BDE and $\mathrm{BDEd})$, the number of $\mathrm{OH}$ groups $(\mathrm{nOH})$; the spin density of the active $\mathrm{OH}$ groups (SD); and the free enthalpy of the reaction of the reactivity of phenolic Schiff bases with the DPPH radical $(\Delta \mathrm{G})$. Work [33] reported that the antioxidant activity of phenols correlates with electron affinity (EA) and hardness $(\eta)$ calculated with AM1 and PM3. The authors of work [34] based on 15 antioxidants built a QSAR model with high values of statistical parameters using enthalpy of homolytic dissociation of $\mathrm{OH}$ bonds (BDE-OH) and ionization potential (IP), and two lipophilic parameters, lipophilicity (LogP) and relative lipophilicity $(\log D)$. In this model, the most pronounced antioxidant effect was found for the compounds with electron-donor groups directly bonded with the aromatic ring. The results of these and other similar studies are fundamental. However, it is incorrect to perform virtual screening with QSAR models based on training samples with less than 30 compounds. Thus, the use of these quantum-chemically calculated descriptors and values of Taft constants, despite of their clear physical meaning, is difficult for wide sets of compounds with different structures, i.e., such approaches are applicable only to training sets of closely related compounds. 
To modelling the large-sized training sets of the diverse compounds, one has to use the methods for calculating descriptors that allow rationalizing the QSAR model development process. GUSAR 2013 (General Unrestricted Structure Activity Relationships) is one of the programs for calculating physicochemical and structural descriptors, selection of the most significant of them and developing a QSAR consensus model based on them [35-38]. This program for the formation of independent descriptors and their selection at the stage of the formation of regression models uses unique approaches, which we describe in detail in Supplementary Materials. The program has demonstrated its efficiency for modeling various types of biological activity [35-46]. It is important to note that GUSAR 2013 allows prompt processing (in a matter of seconds) various structural and physicochemical descriptors, automatic selecting the most significant of them, and develop statistically significant QSAR consensus models. As far as we can judge, GUSAR 2013 was not used for research on the antioxidant activity of QSAR.

In the present work, we have studied a quantitative structure-antioxidant activity relationship in the series of phenols, aminophenols, aromatic amines and uracils with general structural formulas I-V (Figure 1) using the GUSAR 2013 program and constructed the corresponding statistically significant QSAR models for predicting the $\mathrm{k}_{7}$ values.<smiles>[R3]Cc1cccc([Y9])c1[Y9]</smiles>

Figure 1. General structural formulas of the inhibitors under study.

\section{Computational Details}

\subsection{Computational Methodology}

The structures of the phenol, aminophenol and uracil derivatives selected for the QSAR modeling in GUSAR 2013 [35-37,42-47] are shown in Figure 1. A complete list of compounds with their experimental $\mathrm{k}_{7}$ values is presented in Supplementary Materials (Table S2). The experimental data $\mathrm{k}_{7}$ of phenol, aminophenol and uracil derivatives (in $\left.\mathrm{L} \cdot \mathrm{mol}^{-1} \cdot \mathrm{s}^{-1}\right)$ were selected from the literature $[27,48,49]$ and converted to logarithmic values $\left(\lg \mathrm{k}_{7}\right)$ for QSAR analysis.

The QSAR models were built in several steps schematically presented in Figure 2.

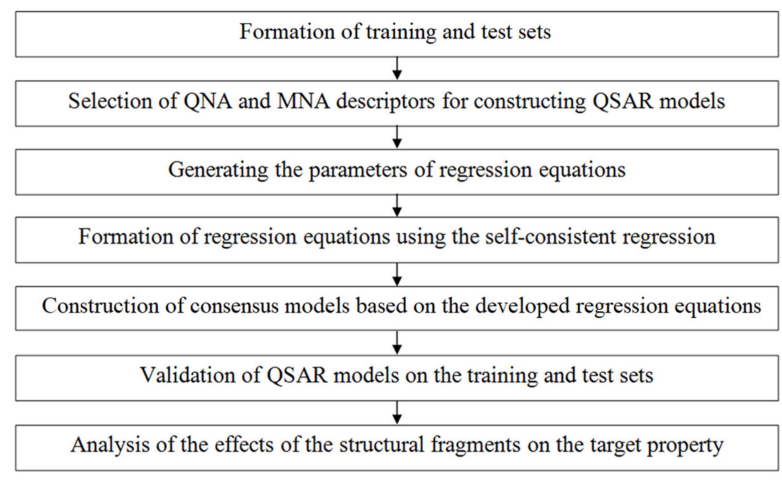

Figure 2. Schematic representation of the GUSAR algorithm. 
Formation of Training and Test Sets

Training (TR1-TR3) and test (TS1-TS2) sets for the development of the models M1-M9 were composed based on the set of 74 compounds (MD1) according to the scheme shown in Figure 3. Set MD1 is made up with the uracil, phenol and aminophenol derivatives, for which the trustworthy $k_{7}$ values are known [48-50]. Thus, the $k_{7}$ values are used as a quantitative parameter for assessing target AOA.

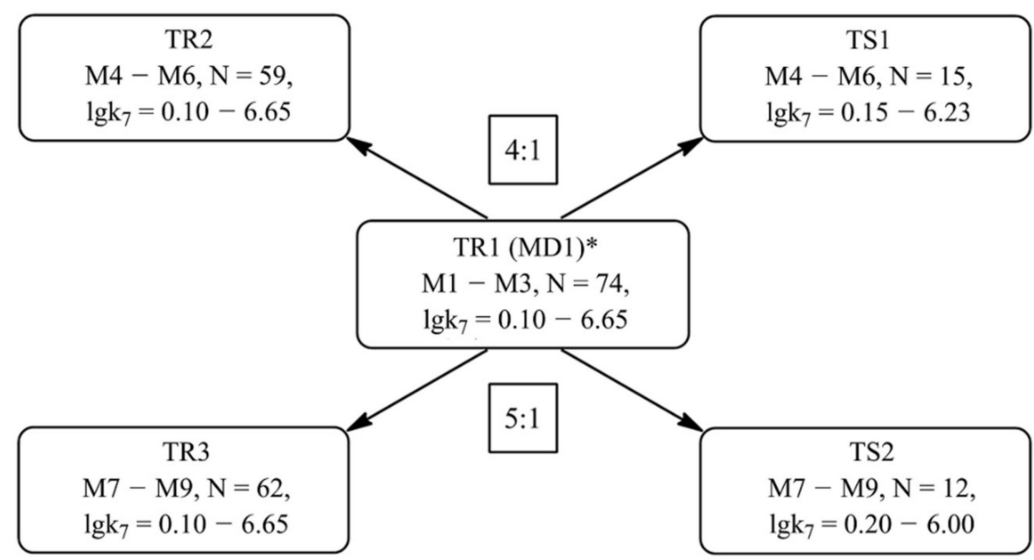

Figure 3. The scheme for the formation of training and test sets for the further development of QSAR models (MD is an array of the data, TR is a training set, TS is a test set, $\mathrm{N}$ is the number of compounds included in the corresponding set). ${ }^{*} \mathrm{MD} 1$ is formed on the data taken from [48-50].

The M1-M3 models were built based on the set TR1, which contains a complete set of antioxidant structures of the MD1 set and their corresponding lgk . The TR2 training set is designed to develop QSAR models M4-M6 and includes 59 antioxidant structures. The TS1 set was used to test the predictabilities of models M4-M6. Both of these sets were obtained by the separation of the TR1 set in the ratio 4:1, i.e., each fifth compound was transferred to TS1 from TR1. Before this, all the structures of TR1 were ranked according to the increase in lgk7 parameter. The features of sets TR1-TR2 and TS1 are presented in Tables 1 and 2. The statistical characteristics presented in these tables indicate a fairly uniform distribution of data in all training and test sets. The average values of the lgk7 parameter and the range of its variation in all training and test sets are numerically close. The observed response values lgk7 of training sets TRi and test sets TSi are similarly distributed around training mean. These facts indicate the correctness of the formation of training and test sets.

Table 1. Statistical characteristics of training sets TR1-TR3.

\begin{tabular}{ccccc}
\hline \multirow{2}{*}{ Value } & Designation of TR & \multicolumn{3}{c}{ Code of the Set } \\
\cline { 3 - 5 } & & $\mathrm{TR1}$ & TR2 & TR3 \\
\hline Number of compounds & $\mathrm{N}$ & 74 & 59 & 62 \\
Mean value of lgk & $\overline{\operatorname{lgk}}$ & & 3.3750 & \\
Spread of lgk & $\Delta \mathrm{lgk}_{7}$ & & 6.5500 & \\
& $\overline{\operatorname{lgk}_{7}} \pm 0.5(\%)$ & 20.2703 & 20.0000 & 16.6667 \\
& $\overline{\operatorname{lgk}_{7}} \pm 1.0(\%)$ & 50.0000 & 46.6667 & 50.0000 \\
Distribution of the observed & $\overline{\operatorname{lgk}} \pm 1.5(\%)$ & 72.9730 & 73.3333 & 75.0000 \\
response values of training sets TRi & $\overline{\operatorname{lgk}} \pm 2.0(\%)$ & 83.7838 & 80.0000 & 83.3333 \\
around training mean (in \%) & $0.10 \times \Delta \operatorname{lgk}_{7}$ & & 0.6550 & \\
& $0.15 \times \Delta \operatorname{lgk}_{7}$ & & 0.9825 & \\
& $0.20 \times \Delta \mathrm{lgk}_{7}$ & & 1.3100 & \\
\hline
\end{tabular}


Table 2. Statistical characteristics of test sets TS1-TS2.

\begin{tabular}{cccc}
\hline Value & Designation of TS & \multicolumn{2}{c}{ Code of the Set } \\
\cline { 2 - 4 } & & $\mathrm{TS1}$ & TS2 \\
\hline Number of compounds & $\overline{\mathrm{lgk}}$ & 15 & 12 \\
Mean value of lgk & $\Delta \mathrm{lgk}_{7}$ & 4.1727 & 4.0821 \\
Spread of lgk & $\overline{\operatorname{lgk}_{7}} \pm 0.5(\%)$ & 53.3333 & 50.0000 \\
& $\overline{\operatorname{lgk}_{7}} \pm 1.0(\%)$ & 73.3333 & 75.0000 \\
Distribution of the observed response values of & $\overline{\operatorname{lgk}_{7}} \pm 1.5(\%)$ & 86.6667 & 83.3333 \\
test sets TSi around test mean (in \%) & $\overline{\operatorname{lgk}_{7}} \pm 2.0(\%)$ & 86.6667 & 91.6667 \\
& $\overline{\operatorname{lgk}_{7}} \pm 0.5(\%)$ & 20.0000 & 16.6667 \\
Distribution of the observed response values of & $\overline{\operatorname{lgk}_{7}} \pm 1.0(\%)$ & 46.6667 & 50.0000 \\
test sets TSi around train mean (in \%) & $\overline{\operatorname{lgk}_{7}} \pm 1.5(\%)$ & 73.3333 & 75.0000 \\
& $\overline{\operatorname{lgk}_{7}} \pm 2.0(\%)$ & 80.0000 & 83.3333 \\
\hline
\end{tabular}

The TR3 set contains 62 inhibitors for the further development of QSAR models M7M9. The validity of these models was assessed using test set TS2. Both of these sets were formed as above, viz. based on TR1. However, in this case, the TR1 set was divided in ratio $5: 1$, so that each sixth compound of TR1 is transferred to TS2. The characteristics of sets TR3 and TS2 are presented in Tables 1 and 2.

The structures of the TR1-TR3 and TS1-TS2 sets were generated in the Marvin Sketch 17.22.0 program [51] and converted to the SDF format using the Discovery Studio Visualiser [52].

The variation of the $\lg k_{7}$ values within the training sets are $\Delta \operatorname{lgk}_{7}>6$. Thus, the condition for development of reliable QSAR models is fulfilled [53].

\subsection{QSAR Model Development}

The QSAR models M1-M9 for quantitative prediction of the antioxidant activity of uracil, phenol, and aminophenol derivatives were based on two types of substructural descriptors of atomic neighborhoods: QNA (Quantitative Neighborhood of Atoms) and MNA (Multilevel Neighborhoods of Atoms) [35-37,42-47]. These descriptors are automatically computed in the GUSAR2013 program based on the structural formulas of chemical compounds, taking into account the valence and partial atomic charges. The peculiarities of chemical bonds are not considered. Let's briefly explain the ideology of calculating descriptors in the program GUSAR2013. The ideology of calculating QNA and MNA descriptors is described in detail Supplementary Materials and papers [35-46]. Additionally, three descriptors of the whole molecule (topological length, topological volume, and lipophilicity) were used to enhance the descriptive and predictive ability of the models.

In the GUSAR 2013 program, the description of the structure and the calculation of the regression coefficients for the further construction of QSAR models is based on the use of two types of substructural descriptors of atomic neighborhoods: MNA (Multilevel Neighborhoods of Atoms) and QNA (Quantitative Neighborhoods of Atoms) [39,40]. They are automatically deduced from the matrices of molecular connectivity, standard ionization potentials (IP) and electron affinities (EA). The QNA descriptors are defined by two functions, $P$ and $Q$. The $P$ and $Q$ values for each atom $i$ are calculated using the following formulae [39]:

$$
\begin{gathered}
\mathrm{P}_{\mathrm{i}}=\mathrm{B}_{\mathrm{i}} \sum_{\mathrm{k}}\left(\exp \left(-\frac{1}{2} \mathrm{C}\right)\right)_{\mathrm{ik}} \mathrm{B}_{\mathrm{k}} \\
\mathrm{Q}_{\mathrm{i}}=\mathrm{B}_{\mathrm{i}} \sum_{\mathrm{k}}\left(\exp \left(-\frac{1}{2} \mathrm{C}\right)\right)_{\mathrm{ik}} \mathrm{B}_{\mathrm{k}} \mathrm{A}_{\mathrm{k}}
\end{gathered}
$$




$$
\mathrm{A}_{\mathrm{k}}=\frac{1}{2}\left(\mathrm{IP}_{\mathrm{k}}+\mathrm{EA}_{\mathrm{k}}\right), \mathrm{B}_{\mathrm{k}}=\left(\mathrm{IP}_{\mathrm{k}}-\mathrm{EA}_{\mathrm{k}}\right)^{-1 / 2}
$$

where $\mathrm{k}$ is the remaining atoms in the molecule, IP is the first ionization potential, EA is the electron affinity for each atom (in $\mathrm{eV}$ ), and $\mathrm{C}$ is the connectivity matrix for the molecule as a whole [46]. The standard values IP and EA of atoms in a molecule were collected from the literature. A detailed description of QNA descriptors is represented in [45].

Thus, the QNA descriptors are calculated taking into account the relationships between all atoms of the structure. These values describe each atom of the molecule but, at the same time, depend on the structure of the molecule as a whole $[45,46]$. The QNA values are the basic information for calculating the Chebyshev 2D polynomials. It is important to note that in the final QSAR models, the independent variables include the mean values of the individual two-dimensional Chebyshev polynomials from the $\mathrm{P}$ and $\mathrm{Q}$ values calculated for all atoms in the molecule. Thus, the regression equations constructed in the GUSAR 2013 program take into account both the specificity and physicochemical properties of each atom entering the training set [41,43-46]. However, QNA descriptors cannot be physically interpreted due to the peculiarities of their calculation. In this regard, they are not explicitly displayed under calculations.

The MNA descriptors are computed using the PASS algorithm (Prediction of Activity Spectra for Substances) [39,40], which predicts approximately 6400 "biological activities" with an accuracy threshold of an average prediction of at least $95 \%$. These descriptors are generated based on the structural formulae of chemical compounds without using any precompiled list of structural fragments [39-41,46]. The authors of the GUSAR 2013 program report that "MNA-descriptors are based on the molecular structure representation, which includes hydrogens according to the valences and partial charges of other atoms and does not specify the types of bonds." They are generated as "a recursively defined sequence:

- $\quad$ zero-level MNA descriptor for each atom is the mark A of the atom itself;

- $\quad$ any next-level MNA descriptor for the atom is the substructure notation $A\left(D_{1} D_{2} \ldots\right.$

$D_{i} \ldots$ ), where Di is the previous-level MNA descriptor for $i-t h$ immediate neighbor of the atom $\mathrm{A}$.

The neighbor descriptors $D_{1} D_{2} \ldots D_{i} \ldots$ are arranged in a unique manner. This may be, for example, a lexicographic sequence. MNA descriptors are generated using an iterative procedure, which results in the formation of structural descriptors that include the first, second, etc. neighborhoods of each atom. The label contains not only information about the type of atom, but also additional information about its belonging to a cyclic or acyclic system, etc. For example, an atom that does not enter a ring is marked with a " - ".

Based on the MNA descriptors using B-statistics, calculated in the PASS program, the biological activity spectrum of a chemical compound is predicted [35,36,42-44].

The output of the PASS program is the probabilities of the activity $(\mathrm{Pa})$ and of inactivity (Pi) of each prognostic result. The difference between these two values (Pa-Pi) for a randomly selected subset of predicted activities is used as independent variables for regression analysis in GUSAR. GUSAR2013 incorporates a PASS version that pedicts 4130 types of biological activity. The developers of the GUSAR 2013 program report that the list of predictable biological activities currently includes 501 pharmacotherapeutic effects, 3295 mechanisms of action, 57 adverse and toxic effects, 199 metabolic terms, 49 transporter proteins and 29 activities related to gene expression [46]. The average accuracy of a reliable prediction of biological activity, calculated by leave-one-out cross-validation procedure is approximately 95\% [54]. However, the regression equation constructed based on the MNA descriptors reveals the specificity of the action of the compound but does not explicitly reflects the physicochemical parameters of chemical compounds [46].

In addition, the GUSAR 2013 program calculated the QSAR descriptors of an entire molecule such as topological length, topological volume, lipophilicity, and physicochemical descriptors (numbers of positive and negative charges, number of donors and acceptors of the hydrogen bond, number of aromatic atoms, molecular weight and number of halogen atoms) $[39,40]$. These parameters were added to the QNA descriptors. The topological 
length of a molecule was calculated as the maximal distance between any two atoms and the volume of a molecule as the sum of each atom's volume, $4 / 3 \pi R^{3}$, where $R$ is the atomic radius [45].

The authors of the GUSAR 2013 program report that "in GUSAR, the scale of QNAand PASS-based descriptors ranges from -1 to 1 . Therefore, no additional normalization is required for these types of descriptors. Only whole-molecule descriptors are normalized using a standard Z-score normalization procedure" [40].

It should be noted that the program is able to construct QSAR models both relying solely on one of these types of descriptors, and on their combination in terms of the consensus approach [42-44]. At the same time, based on the consensus approach methodology, models for quantitative prediction of biological activity for these descriptors are calculated independently of each other. The examples of the sample QSAR GUSAR models for predicting the toxic effects of chemical compounds are available free via the link http:/ / www.way2drug.com/GUSAR.

However, it noteworthy that the features of the QNA and MNA calculations retain these descriptors without unambiguous physical interpretation. For this reason, in the commercial and academic versions of the GUSAR 2013 program for broad use, the regression equations are not displayed.

To reduce the descriptor space and select the most significant descriptors, the RBFSCR method was used, which combines the advantages of the radial basis function (RBF) interpolation and the self-consistent regression (SCR) method. It has a 3-step algorithm:

(1) Selecting descriptors using the SCR method. This is a regularized method of the least squares. Independent parameters $a$ are calculated in this method according to the Equation (4) [43]:

$$
\left.\mathrm{a}=\operatorname{ArgMin}\left[\sum_{\mathrm{i}=1}^{n} \mathrm{y}_{\mathrm{i}}-\sum_{\mathrm{k}=0}^{\mathrm{m}} \mathrm{x}_{\mathrm{ik}} \mathrm{a}_{\mathrm{k}}\right)^{2}+\sum_{\mathrm{k}=1}^{\mathrm{m}} \mathrm{v}_{\mathrm{k}} \mathrm{a}_{\mathrm{k}}^{2}\right]
$$

where $\mathrm{a}$ is the regression coefficient, $\mathrm{n}$ is the number of objects, $\mathrm{y}_{\mathrm{i}}$ is the response value of the $i$-th object, $m$ is the number of independent variables, $x_{i k}$ is the value of the $k$-th independent variable of the $i$-th object, $a_{k}$ is the $k$-th value of the regression coefficients, and $\mathrm{v}_{\mathrm{k}}$ is the $\mathrm{k}$-th value of the regularization parameters. Equation (4) has the following solution:

$$
\mathrm{a}=\mathrm{TX}^{\mathrm{T}} \mathrm{y}, \mathrm{T}=\left(\mathrm{X}^{\mathrm{T}} \mathrm{X}+\mathrm{V}\right)^{-1}
$$

where $\mathrm{X}^{\mathrm{T}}$ is the transposed regression matrix $\mathrm{X}$, and $\mathrm{V}$ is the diagonal matrix of the regularization parameters. The regression coefficients obtained from the SCR reflect the contribution of each particular descriptor (variable) to the final equation. The higher the absolute value of the coefficient, the greater its contribution. Thus, the regression coefficients obtained after the SCR can be used to weight the descriptors (variables) depending on their importance.

(2) Calculating the radial basis functions using the weighted coefficient of SCR as a criterion of similarity. The RBF-SCR method can be expressed as [39]:

$$
\mathrm{y}(\mathrm{x})=\sum_{\mathrm{i}=1}^{\mathrm{N}} \mathrm{w}_{\mathrm{i}} \varphi\left(\left\|\mathrm{ax}-\mathrm{a}_{\mathrm{i}} \mathrm{x}_{\mathrm{i}}\right\|\right)=\Phi \mathrm{w}
$$

where a is taken from Equation (4).

The weights $\mathrm{w}$ are calculated as:

$$
\mathrm{w}=\Phi^{-1} \mathrm{y}
$$

(3) Calculating the weighting coefficients RBF by the least squares. 
The authors of the GUSAR 2013 program report [39] that, in contrast to the RBF network, in the RBF-SCR method each input variable is used as a center of gravity. The learning process is performed on all input variables of the training set. The RBF-SCR interpolation is based on a linear radial basis function that allows modeling a variety of training sets with a high level of dissimilarity between the objects.

It is shown that such a combined method of selecting descriptors in regression models provides more accurate prediction results as compared with the individual SCR and RBF methods, even if they are used in the consensus approach [39]. A detailed description of this method is available in Supplementary Materials and paper [39].

Additionally, the adequacy of the constructed models was tested using cross-validation procedure with 20 -fold randomized release of $20 \%$ of compounds from the training sets (20-fold CV, leave-many-out procedure). Both procedures are automatic in the GUSAR 2013 program [35-47].

Each of the six final QSAR consensus models M1-M2, M4-M5, M7-M8 include 20 partial regression equations automatically united based on their similarity. M1, M4, M7 models were built based on the QNA descriptors with automatic addition of the topological lengths, topological volumes and lipophilicities of the simulated antioxidant structures. M2, M5, M8 models were similarly built based on the MNA descriptors with addition of the abovementioned molecular descriptors. Models M3, M6 and M9 were built guiding the same principle. Each of these models included 320 partial regressions, which were built independently of each other based on QNA or MNA descriptors. Note that the regression equations operating with QNA and MNA descriptors have no direct physical interpretation and, therefore, are not displayed in GUSAR 2013. The final prediction of the $1 g \mathrm{k}_{7}$ values for a particular compound is formed on the averaged predicted lgk7 values of the partial QSAR regression models.

Applicability domain estimation of the constructed models was performed with three different approaches: similarity, leverage and accuracy described in detail in Supplementary Materials.

As we have built the QSAR consensus model containing 20-100 single models, it is impossible to provide a general equation that would allow describing all selected variables. For this reason, such QSAR models cannot provide information about positive and negatively affecting descriptors. Instead, the GUSAR program allows evaluating the contribution of each atom of the structure to the target property.

\subsection{Assessment of the Descriptive and Predictive Ability of QSAR Models}

The descriptive ability of the QSAR models M1-M9 and the corresponding systematic errors were estimated by the predicted $\lg \mathrm{k}_{7}$ values for the structures of TR1-TR3 using a metrics based on the determination coefficients of $R^{2}\left(R^{2} T_{S i}, R^{2}{ }_{0}, \overline{R_{m T S i}^{2}}\right)$ and based on the concordance correlation coefficient (CCC). The prognostic ability of these models was assessed with the predicted $\lg _{7}$ values for the structures of test sets TS1 and TS2 using the metrics of two categories: (1) based on the determination coefficients $R^{2}\left(R^{2} T_{S i}, R^{2}{ }_{0}\right.$, $\mathrm{Q}^{2}(\mathrm{~F} 1), \mathrm{Q}^{2}(\mathrm{~F} 2), \overline{\mathrm{R}_{\mathrm{mTSi}}^{2}}$ and CCC); or (2) based on the prediction lgk 7 errors (root mean square error (RMSEP), mean absolute error (MAE) and standard deviation (S.D.)) [55-59]. The calculations of these statistical parameters were performed using the Xternal Validation Plus 1.2 program [60].

Additionally, the prognostic abilities of the QSAR consensus model were estimated by comparing the predicted and known experimental lgk $\mathrm{k}_{7}$ values for $N$-2-ethylhexyl- $N^{\prime}$ phenyl-p-phenylenediamine (8-PPDA), a promising industrial antioxidant, which was not included in the data array MD1. The experimental $\lg k_{7}$ values for this compound were measured by a manometric method based on the absorption of atmospheric oxygen using the model liquid-phase ethylbenzene oxidation initiated by azodiisobutyronitrile (AIBN) at $348 \mathrm{~K}$. The kinetic curves were recorded using a universal manometric differential device [61-66]. 
In these experiments, the rate constant of chain termination $f \mathrm{k}_{7}$ was a quantitative parameter of AOA, where $f$ is the inhibitor capacity, equal to the number of radical intermediates decaying in the interaction with one inhibitor molecule (8-PPDA) [14]. This kinetic parameter was determined by the concentration effect of 8-PPDA on the oxidation rate of ethylbenzene, a model substrate. When analyzing the experimental data, we used the basic mechanism of the inhibited radical-chain oxidation of organic compounds (Scheme 1) [14,27].

$$
\begin{aligned}
& \ldots I \rightarrow r^{\bullet} \\
& r^{\bullet}+R H \rightarrow r H+R^{\bullet} \\
& R^{\bullet}+O_{2} \rightarrow R_{2}^{\bullet} \\
& R H+\mathrm{RO}_{2}^{\bullet} \rightarrow \mathrm{R}^{\bullet}+\mathrm{ROOH} \\
& \mathrm{RO}_{2}^{\bullet}+\mathrm{RO}_{2}^{\bullet} \rightarrow \mathrm{O}_{2}+\mathrm{ROOH} \\
& \mathrm{InH}+\mathrm{RO}_{2}^{\bullet} \rightarrow \mathrm{ROOH}+\mathrm{In}^{\bullet}
\end{aligned}
$$

Scheme 1. I, RH and InH are the initiator, oxidized substrate and inhibitor, respectively.

\section{Results and Discussion}

Based on the consensus approach implemented in the GUSAR 2013 program, the quantitative relationship between the structure and antioxidant activity of uracil, phenol and aminophenol derivatives of sets TR1-TR3 was modeled. Depending on the type of the used descriptors, three QSAR consensus models have been built for each of these training sets. The descriptive and predictive abilities of these models were estimated on the structures of TR1-TR3 by cross-validation with 20-fold randomized exception of $20 \%$ of compounds and using the structures of the test sets. The descriptive parameters of consensus models M1-M9, calculated automatically in the GUSAR 2013 program based on a comparison of the experimental and predicted $\operatorname{lgk}_{7}$ values for these nine models are presented in Table 3. The experimental and predicted $\operatorname{lgk}_{7}$ values used for calculating the statistical parameters of models M1-M9 are collected in Supplementary Materials (Tables S3-S7).

Table 3. Statistical parameters and accuracy of the predicted $l g k_{7}$ values of the compounds from training sets TR1-TR3 within the M1-M9 consensus models (using RBF-SCR). $\Delta \operatorname{lgk}_{7}$ (TR1) $=\Delta \operatorname{lgk}_{7}$ (TR2) $=\Delta \lg \mathrm{k}_{7}(\mathrm{TR} 3)=6.55 .^{1}$

\begin{tabular}{ccccccccc}
\hline Training Set & Model & $\mathbf{N}$ & $\mathbf{N}_{\mathbf{P M}}$ & $\overline{\mathbf{R}^{2}}$ & $\overline{\mathbf{F}}$ & $\overline{\mathbf{S . D}}$ & $\overline{\mathbf{Q}^{2}}$ & $\mathbf{V}$ \\
\hline \multicolumn{7}{c}{ QSAR Models Based on the QNA Descriptors } \\
\hline TR1 & M1 & 74 & 20 & 0.999 & 10.457 & 0.525 & 0.843 & 22 \\
TR2 & M4 & 59 & 20 & 0.999 & 7.676 & 0.587 & 0.799 & 18 \\
TR3 & M7 & 62 & 20 & 0.999 & 6.059 & 0.544 & 0.829 & 24 \\
\hline \multicolumn{7}{c}{ QSAR Models Based on the MNA Descriptors } \\
TR1 & M2 & 74 & 20 & 0.999 & 18.207 & 0.478 & 0.867 & 18 \\
TR2 & M5 & 59 & 20 & 0.998 & 11.554 & 0.556 & 0.819 & 15 \\
TR3 & M8 & 62 & 20 & 0.999 & 9.864 & 0.567 & 0.810 & 17 \\
\hline TR1 & QSAR Models Based on Both QNA and MNA Descriptors & & \\
TR2 & M3 & 74 & 100 & 0.999 & 10.744 & 0.490 & 0.872 & 22 \\
TR3 & M6 & 59 & 100 & 0.999 & 7.768 & 0.559 & 0.830 & 18 \\
\hline
\end{tabular}

${ }^{1} \mathrm{~N}$ is the number of structures in the training set; $\mathrm{N}_{\mathrm{PM}}$ is the number of regression equations used for the consensus model; $\overline{\mathrm{R}^{2}}$ is the determination coefficient calculated for the compounds of $\mathrm{TR}_{\mathrm{i}} ; \overline{\mathrm{Q}^{2}}$ is the correlation coefficient calculated for the training set with the by cross-validation with exception of one; $\overline{\mathrm{F}}$ is the Fisher criterion; $\overline{\text { S.D. }}$ - standard deviation; $\mathrm{V}$ is the number of variables in the final regression equation. 
Note that Table 3 contains the averaged values of determination coefficients, RMSD and Fisher criterion obtained with all partial regression models included in the consensus model $\mathrm{M}_{\mathrm{i}}$.

To estimate the predictive power of the method underlying the GUSAR 2013 models, we used two test sets of antioxidants. The models obtained via the computation procedures with three training sets are used to predict the activity of compounds from TS1 and TS2. As an example, the plot of the predicted $l g k_{7}$ values based on models M3, M6 and M9 versus experimental ones is shown in Figure 4. Dependencies depicted in this figure clearly indicate a fairly high descriptive and predictive ability of models M3, M6 and M9.

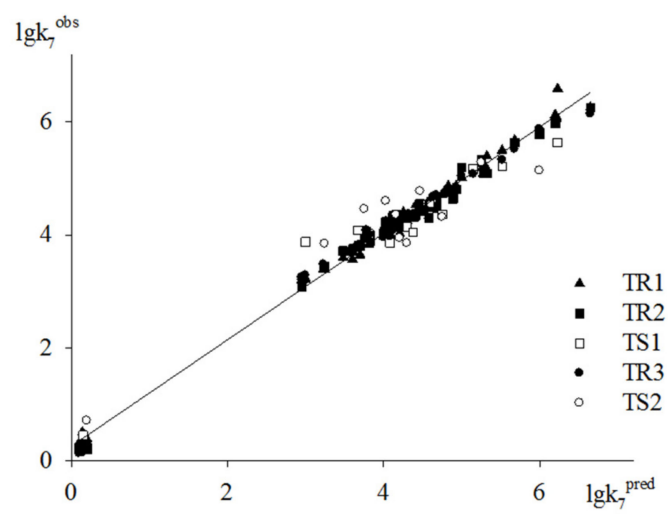

Figure 4. Plot of predicted activities vs. experimental ones based on Models M3, M6 and M9.

Meanwhile, the averaged values of the coefficients of determination, standard deviation and the Fisher criterion are not sufficient for the reliable characterization of the descriptive and predictive abilities of models M1-M9. Therefore, according to recommendations $[39,58,59]$, we used the metrics of two categories in addition to the GUSAR 2013 parameters. These are (1) metrics based on the coefficients of determination $R^{2}\left(R^{2} T_{S i}, R^{2}{ }_{0}\right.$, $\left.\mathrm{Q}^{2}(\mathrm{~F} 1), \mathrm{Q}^{2}(\mathrm{~F} 2), \overline{\mathrm{R}_{\mathrm{mTSi}}^{2}}, \mathrm{CCC}\right)$; and (2) metrics that allow estimating prediction errors of $\operatorname{lgk} 7$ values (RMSEP, MAE, S.D.) [53,55-59]. These statistical parameters were calculated using the Xternal Validation Plus 1.2 program [60]. Additionally, in this program, we estimated the systematic errors of the models.

We considered that the QSAR model $M_{i}$ possesses a high descriptive ability if its determination coefficients of different types for $95 \%$ of the data $\mathrm{TR}_{\mathrm{i}}$ are close to each other and tend to unity.

We considered that the QSAR model $M_{i}$ possesses a high predictive ability if the following four conditions are simultaneously fulfilled for $95 \%$ of the test sets:

(1) determination coefficients $\mathrm{R}^{2}, \mathrm{R}^{2}{ }_{0}, \mathrm{R}^{2 \prime}{ }_{0}, \mathrm{Q}^{2} \mathrm{~F} 1, \mathrm{Q}^{2} \mathrm{~F} 2$ and $\mathrm{CCC}$ criterion are close to each other and tend to unity;

(2) $\mathrm{R}^{2}{ }_{\mathrm{m}}>0.5$ if $\Delta \mathrm{R}^{2}{ }_{\mathrm{m}}<0.2$;

(3) MAE value does not exceed $10 \%$ of the $\Delta \lg \mathrm{k}_{7}$ interval of the compounds from $\mathrm{TR}_{\mathrm{i}}$;

(4) the sum MAE + 3.S.D. does not exceed $20 \%$ of the $\Delta \operatorname{lgk} \mathrm{k}_{7}$ interval of the compounds from $\mathrm{TR}_{\mathrm{i}}$.

We considered that the QSAR model $\mathrm{M}_{\mathrm{i}}$ has a low predictive ability if the following four conditions are simultaneously fulfilled for $95 \%$ of the test sets:

(1) determination coefficients $\mathrm{R}^{2}, \mathrm{R}^{2}{ }_{0}, \mathrm{R}^{2 \prime}{ }_{0}, \mathrm{Q}^{2} \mathrm{~F} 1, \mathrm{Q}^{2} \mathrm{~F} 2$ and $\mathrm{CCC}$ criterion do not exceed the threshold value equal to 0.6 ;

(2) $\quad \mathrm{R}^{2}{ }_{\mathrm{m}} \leq 0.5$ if $\Delta \mathrm{R}^{2}{ }_{\mathrm{m}} \leq 0.2$;

(3) MAE value is higher than $15 \%$ of the $\Delta \operatorname{lgk} 7$ interval of the compounds from $\mathrm{TR}_{\mathrm{i}}$;

(4) the sum MAE + 3.S.D. is larger than $25 \%$ of the $\Delta \operatorname{lgk}_{7}$ interval of the compounds from $\mathrm{TR}_{\mathrm{i}}$.

Otherwise, we considered the descriptive and predictive abilities of the models as moderate. 
Statistical criteria of the descriptive and predictive abilities of the QSAR models M1M9 deduced from comparing experimental and predicted $\operatorname{lgk}_{7}$ are presented as diagrams (Figures 5 and 6). The full set of the calculated statistical parameters for the TR1-TR3 and TS1-TS2 structures is available as Supplementary Materials (Tables S3-S7). The diagrams demonstrate that models M1-M9 possess high descriptive and predictive abilities.

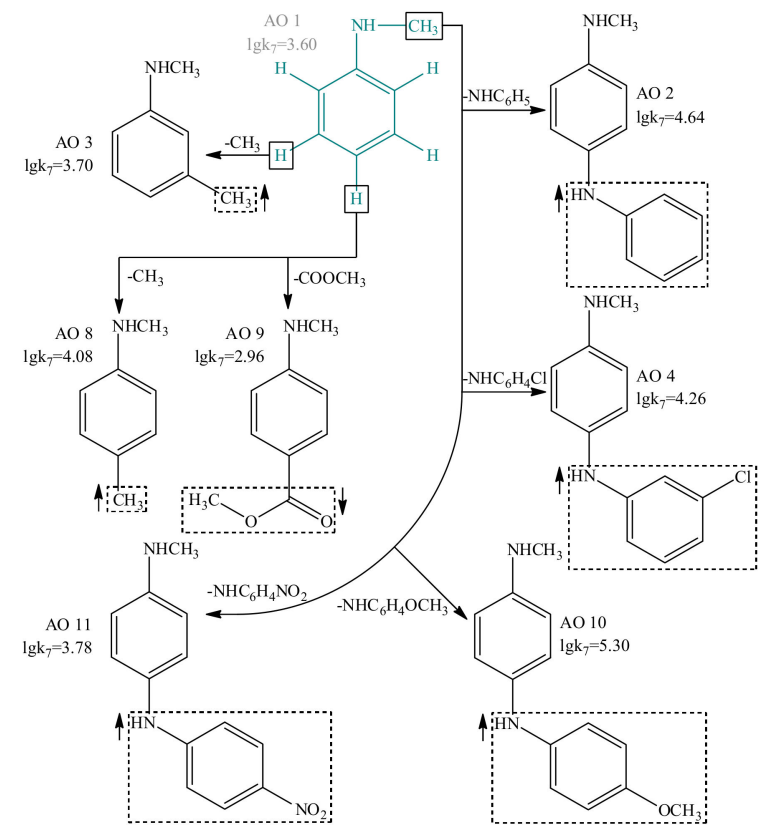

Figure 5. The effect of structural features on the antioxidant activity of compounds with general structural formula I.

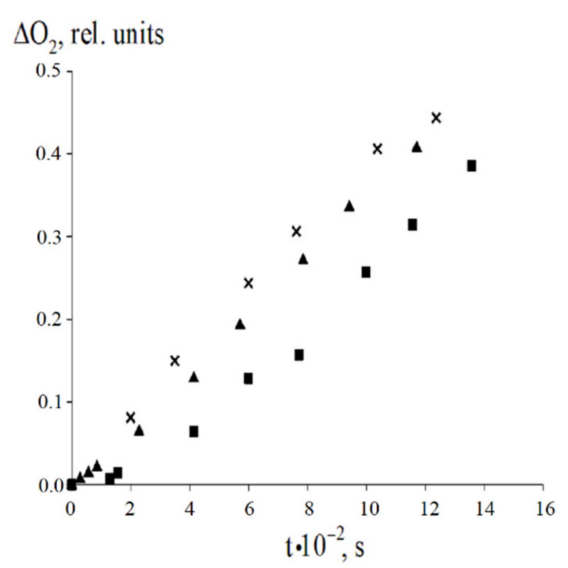

(a)

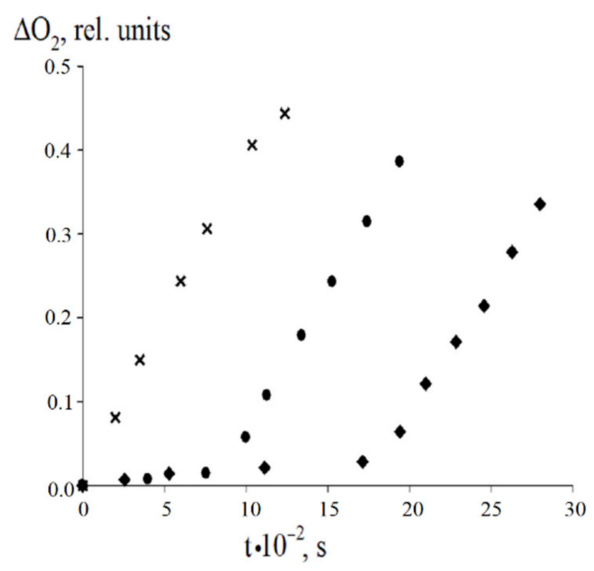

(b)

Figure 6. The kinetic curves of the oxygen absorption upon the ethylbenzene oxidation $\left(\mathrm{V}_{\mathrm{i}}=\right.$ $\left.2.4 \cdot 10^{-7} \mathrm{~mol} \cdot \mathrm{L}^{-1} \cdot \mathrm{s}^{-1}, 348 \mathrm{~K}\right)$ without $(\times)$ and with 8 -PPDA: (a) $2 \times 10^{-5} \mathrm{~mol} \cdot \mathrm{L}^{-1}(\mathbf{\Delta})$ and $4.03 \times$ $10^{-5} \mathrm{~mol} \cdot \mathrm{L}^{-1}$

(口); (b) $1 \times 10^{-4} \mathrm{~mol} \cdot \mathrm{L}^{-1}(\bullet)$ and $1.61 \times 10^{-4} \mathrm{~mol} \mathrm{~L}^{-1}$

A slight difference between the different determination coefficients in combination with appropriate MAE and MAE + 3.S.D. values (Tables 4 and 5) suggests that valid QSAR models for the AOA prediction can be built using one specific type of descriptors (QNA/MNA) or their combinations.

In addition, using the GUSAR 2013 program and comparative analysis of the experimental data, we have systematically studied model antioxidants I-V and elucidated the functional groups, which are able to modulate the $\operatorname{lgk}_{7}$ values. Figure 5 shows the structures of 7 compounds with the general structural formula I used for the comparative analysis. 
More detailed information on the effect of functional groups on the antioxidant activity of compounds with the general structural formulas I-V is presented in Supplementary Materials (Figures S1-S10, Tables S8-S9).

In general, the results of the structural analysis using the GUSAR 2013 program are consistent with the literature data on the effect of various ortho, meta, and para substituents on the antioxidant activity of compounds I-V. Particularly, the introduction of electron-donor substituents in the ortho, meta, and para positions of I-IV increases the $\operatorname{lgk}_{7}$ parameter. At the same time, electron-acceptor substituents in the same positions lead to the opposite effect. In compounds $\mathrm{V}$, the effect of electron-donor substituents is ambiguous. Methyl groups in positions $R_{1}, R_{2}, R_{3}$ increase the nominal value of $l g k_{7}$ but replacing the hydrogen atom from positions $R_{1}$ and $R_{2}$ by the hydroxyl or amino group, in contrast, reduces the antioxidant properties. A detailed description of this fact is presented in Supplementary Materials (Figure S6). Uracil derivatives with electronacceptor substituents in $R_{1}, R_{2}, R_{3}$ and $R_{4}$ positions are not used in the modeling, and for this reason not discussed [61].

Then we have applied the consensus models M3, M6 and M9 to predicting the lgk 7 parameter of 8-PPDA, an aromatic amine antioxidant. We choose these models for this purpose as they are based on the descriptors of different types and, therefore, expected to provide more accurate estimates. The results of the lgk7 calculation for 8-PPDA within the M3, M6 and M9 models are shown in Table 6.

Table 4. The validation parameters of the QSAR models estimated using the Xternal Validation Plus 1.2 program based on the experimental and predicted $\lg \mathrm{k}_{7}$ values of the compounds form test sets TS1 and TS2. $\Delta \lg \mathrm{k}_{7(\mathrm{TR} 1)}=\Delta \operatorname{lgk} \mathrm{k}_{7(\mathrm{TR} 2)}=$ $\Delta \lg \mathrm{k}_{7(\mathrm{TR} 3)}=6.55 ; \Delta \lg \mathrm{k}_{7(\mathrm{TS} 1)}=6.08 ; \Delta \lg \mathrm{k}_{7(\mathrm{TS} 2)}=5.80 .{ }^{1}$

\begin{tabular}{|c|c|c|c|c|c|c|c|c|c|c|}
\hline \multirow{3}{*}{ Comments } & \multirow{3}{*}{$\begin{array}{l}\text { Prediction } \\
\text { Parameters }\end{array}$} & \multicolumn{9}{|c|}{ QSAR Model Used for Predicting lgk } \\
\hline & & \multicolumn{3}{|c|}{ TR1 } & \multicolumn{3}{|c|}{ TR2 } & \multicolumn{3}{|c|}{ TR3 } \\
\hline & & M1 & M2 & M3 & M4 & M5 & M6 & M7 & M8 & M9 \\
\hline \multirow{6}{*}{ Classical Metrics ( $100 \%$ data) } & $\mathrm{R}^{2}$ & 0.9894 & 0.9922 & 0.9923 & 0.9878 & 0.9897 & 0.9899 & 0.9888 & 0.9902 & 0.9893 \\
\hline & $\mathrm{R}_{0}^{2}$ & 0.9887 & 0.9906 & 0.9894 & 0.9869 & 0.9888 & 0.9876 & 0.9876 & 0.9890 & 0.9871 \\
\hline & $\mathrm{R}^{2^{\prime}}{ }_{0}$ & 0.9878 & 0.9899 & 0.9881 & 0.9860 & 0.9881 & 0.9863 & 0.9866 & 0.9882 & 0.9856 \\
\hline & $\overline{\mathrm{R}_{\mathrm{m}}^{2}}$ & 0.9538 & 0.9568 & 0.9387 & 0.9520 & 0.9550 & 0.9369 & 0.9493 & 0.9514 & 0.9357 \\
\hline & $\Delta \mathrm{R}^{2}{ }_{\mathrm{m}}$ & 0.0120 & 0.0101 & 0.0115 & 0.0128 & 0.0109 & 0.0123 & 0.0122 & 0.0108 & 0.0129 \\
\hline & $\mathrm{CCC}$ & 0.9947 & 0.996 & 0.9952 & 0.9929 & 0.9942 & 0.9934 & 0.9932 & 0.9942 & 0.9930 \\
\hline \multirow{6}{*}{$\begin{array}{l}\text { Classical Metrics (after } \\
\text { removing } 5 \% \text { data with } \\
\text { high residuals) }\end{array}$} & $\mathrm{R}^{2}$ & 0.9917 & 0.9939 & 0.9936 & 0.9899 & 0.9921 & 0.9918 & 0.9922 & 0.9936 & 0.9928 \\
\hline & $\mathrm{R}_{0}^{2}$ & 0.9911 & 0.9932 & 0.9918 & 0.9893 & 0.9914 & 0.9900 & 0.9917 & 0.9931 & 0.9913 \\
\hline & $\mathrm{R}^{2^{\prime}}{ }_{0}$ & 0.9571 & 0.9589 & 0.9420 & 0.9553 & 0.9571 & 0.9402 & 0.9628 & 0.9648 & 0.9467 \\
\hline & $\overline{\mathrm{R}_{\mathrm{m}}^{2}}$ & 0.9624 & 0.9632 & 0.9470 & 0.9606 & 0.9614 & 0.9452 & 0.9670 & 0.9683 & 0.9511 \\
\hline & $\Delta \mathrm{R}^{2}{ }_{\mathrm{m}}$ & 0.0094 & 0.0074 & 0.0089 & 0.0104 & 0.0084 & 0.0099 & 0.0080 & 0.0067 & 0.0085 \\
\hline & $\mathrm{CCC}$ & 0.9962 & 0.9973 & 0.9965 & 0.9944 & 0.9955 & 0.9947 & 0.9956 & 0.9962 & 0.9954 \\
\hline \multirow{4}{*}{$\begin{array}{c}\text { Mean absolute error and } \\
\text { standard deviation for test set } \\
(100 \% \text { data })\end{array}$} & RMSE & 0.1341 & 0.1195 & 0.1277 & 0.1518 & 0.1372 & 0.1454 & 0.1466 & 0.1364 & 0.1486 \\
\hline & MAE & 0.1014 & 0.0894 & 0.0997 & 0.1132 & 0.1012 & 0.1115 & 0.1060 & 0.0976 & 0.1103 \\
\hline & S.D. & 0.0920 & 0.0834 & 0.0841 & 0.1020 & 0.0934 & 0.0941 & 0.1021 & 0.0960 & 0.1004 \\
\hline & MAE+3·S.D. & 0.3774 & 0.3396 & 0.3520 & 0.4192 & 0.3814 & 0.3938 & 0.4123 & 0.3856 & 0.4115 \\
\hline \multirow{4}{*}{$\begin{array}{l}\text { Mean absolute error and } \\
\text { standard deviation for test set } \\
\text { (after removing } 5 \% \text { data with } \\
\text { high residuals) }\end{array}$} & RMSE & 0.1284 & 0.1192 & 0.1247 & 0.1326 & 0.1234 & 0.1289 & 0.1180 & 0.1095 & 0.1203 \\
\hline & MAE & 0.0982 & 0.0889 & 0.099 & 0.1003 & 0.0910 & 0.1003 & 0.0887 & 0.0812 & 0.0936 \\
\hline & S.D. & 0.0853 & 0.0821 & 0.0795 & 0.0874 & 0.0842 & 0.0816 & 0.0785 & 0.0741 & 0.0762 \\
\hline & MAE+3·S.D. & 0.3541 & 0.3352 & 0.3375 & 0.3627 & 0.3436 & 0.3453 & 0.3241 & 0.3036 & 0.3222 \\
\hline \multirow{4}{*}{$\begin{array}{l}\text { Distribution of prediction } \\
\text { errors (in \%) }\end{array}$} & $\omega \mathrm{N}$ in range $0.10 \times \Delta \operatorname{lgk}_{7}(\mathrm{TR})$ & $0.000^{\mathrm{a}}$ & $0.000^{\mathrm{a}}$ & $0.000^{\mathrm{a}}$ & $0.000^{b}$ & $0.000^{b}$ & $0.000^{b}$ & $0.000^{c}$ & $0.000^{c}$ & $0.000^{\mathrm{c}}$ \\
\hline & $\omega \mathrm{N}$ in range $0.15 \times \Delta \operatorname{lgk}_{7}(\mathrm{TR})$ & $0.000^{\mathrm{a}}$ & $0.000^{\mathrm{a}}$ & $0.000^{\mathrm{a}}$ & $0.000^{\mathrm{b}}$ & $0.000^{\mathrm{b}}$ & $0.000^{\mathrm{b}}$ & $0.000^{\mathrm{c}}$ & $0.000^{\mathrm{c}}$ & $0.000^{\mathrm{c}}$ \\
\hline & $\omega \mathrm{N}$ in range $0.20 \times \Delta \operatorname{lgk}_{7}(\mathrm{TR})$ & $0.000^{\mathrm{a}}$ & $0.000^{\mathrm{a}}$ & $0.000^{\mathrm{a}}$ & $0.000^{\mathrm{b}}$ & $0.000^{\mathrm{b}}$ & $0.000^{\mathrm{b}}$ & $0.000^{c}$ & $0.000^{\mathrm{c}}$ & $0.000^{\mathrm{c}}$ \\
\hline & $\omega \mathrm{N}$ in range $0.25 \times \Delta \operatorname{lgk}_{7(\mathrm{TR})}$ & $0.000^{\mathrm{a}}$ & $0.000^{\mathrm{a}}$ & $0.000^{\mathrm{a}}$ & $0.000^{b}$ & $0.000^{b}$ & $0.000^{b}$ & $0.000^{c}$ & $0.000^{c}$ & $0.000^{\mathrm{c}}$ \\
\hline Prediction quality & - & \multicolumn{9}{|c|}{ Good } \\
\hline Systematic error presence & - & \multicolumn{9}{|c|}{ Absent } \\
\hline
\end{tabular}

${ }^{1}$ Where $R^{2}, R_{0}^{2}$, and $R^{\prime 2}$ are determination coefficients calculated with and without taking into account the origin; $\overline{R_{m}^{2}}$ is the averaged determination coefficient of the regression function, calculated using values of determination coefficients on the ordinate axis ( $\mathrm{R}^{2} \mathrm{~m}$ ) and using them on the abscissa $\left(\mathrm{R}^{\prime 2} \mathrm{~m}\right)$ respectively; $\Delta \mathrm{R}_{\mathrm{m}}^{2}$ is the difference between $\mathrm{R}^{2}{ }_{\mathrm{m}}$ and $\mathrm{R}^{\prime 2} \mathrm{~m}$; CCC is the concordance correlation coefficient; MAE is the mean absolute error; S.D. is the standard deviation; $\omega$ Nis the percentage of training sets TR1-TR3, for which the prediction error is less than the interval proportional to $0.1,0.15,0.20$, and 0.25 of $\Delta \operatorname{lgk}_{7}$ of training sets TR1 (a), TR2 (b) and TR4 (c). 
Table 5. The validation parameters of the QSAR models estimated using the Xternal Validation Plus 1.2 program based on the experimental and predicted $\operatorname{lgk}_{7}$ values of the compounds form training sets $\operatorname{TrS1}-\operatorname{TrS3}{ }^{1} ; \Delta \operatorname{lgk}{ }_{7(\mathrm{TR} 1)}=\Delta \operatorname{lgk} \mathrm{k}_{7(\mathrm{TR} 2)}=$ $\Delta \lg \mathrm{k}_{7(\mathrm{TR} 3)}=6.55 .{ }^{1}$

\begin{tabular}{|c|c|c|c|c|c|c|c|}
\hline \multirow{3}{*}{ Comments } & \multirow{3}{*}{$\begin{array}{l}\text { Prediction } \\
\text { Parameters }\end{array}$} & \multicolumn{6}{|c|}{ QSAR Model Used for Predicting lgk 7} \\
\hline & & \multicolumn{3}{|c|}{ TS1 } & \multicolumn{3}{|c|}{ TS2 } \\
\hline & & M4 & M5 & M6 & M7 & M8 & M9 \\
\hline \multirow{8}{*}{ Classical Metrics (100\% data) } & $\mathrm{R}^{2}$ & 0.9469 & 0.9461 & 0.9388 & 0.8639 & 0.8797 & 0.8876 \\
\hline & $\mathrm{R}_{0}^{2}$ & 0.9360 & 0.9423 & 0.9260 & 0.8638 & 0.8769 & 0.8737 \\
\hline & $\mathrm{R}^{2^{\prime}}{ }_{0}$ & 0.9164 & 0.9312 & 0.9005 & 0.8413 & 0.8454 & 0.8184 \\
\hline & $\mathrm{Q}^{2} \mathrm{~F} 1$ & 0.9531 & 0.9579 & 0.9454 & 0.8931 & 0.9031 & 0.9006 \\
\hline & $\mathrm{Q}^{2} \mathrm{~F} 2$ & 0.9357 & 0.9423 & 0.9251 & 0.8638 & 0.8766 & 0.8734 \\
\hline & $\overline{\mathrm{R}_{\mathrm{m}}^{2}}$ & 0.8152 & 0.8592 & 0.7941 & 0.7951 & 0.7754 & 0.7188 \\
\hline & $\Delta \mathrm{R}^{2}{ }_{\mathrm{m}}$ & 0.0663 & 0.0570 & 0.0771 & 0.1208 & 0.1155 & 0.1285 \\
\hline & $\mathrm{CCC}$ & 0.9634 & 0.9686 & 0.9566 & 0.9263 & 0.9306 & 0.9254 \\
\hline \multirow{8}{*}{$\begin{array}{l}\text { Classical Metrics (after removing } \\
5 \% \text { data with high residuals) }\end{array}$} & $\mathrm{R}^{2}$ & 0.9710 & 0.9715 & 0.9659 & 0.8846 & 0.9106 & 0.9046 \\
\hline & $\mathrm{R}_{0}^{2}$ & 0.9643 & 0.9700 & 0.9575 & 0.8840 & 0.9100 & 0.8963 \\
\hline & $\mathrm{R}^{2^{\prime}}$ & 0.8550 & 0.9051 & 0.8334 & 0.8045 & 0.8043 & 0.7186 \\
\hline & $\mathrm{Q}^{2} \mathrm{~F} 1$ & 0.9731 & 0.9784 & 0.9670 & 0.8959 & 0.9197 & 0.9038 \\
\hline & $\mathrm{Q}^{2} \mathrm{~F} 2$ & 0.9610 & 0.9687 & 0.9521 & 0.8778 & 0.9057 & 0.8870 \\
\hline & $\overline{\mathrm{R}_{\mathrm{m}}^{2}}$ & 0.8739 & 0.9202 & 0.8562 & 0.8342 & 0.8455 & 0.7694 \\
\hline & $\Delta \mathrm{R}^{2}{ }_{\mathrm{m}}$ & 0.0364 & 0.0292 & 0.0437 & 0.0607 & 0.0835 & 0.1035 \\
\hline & CCC & 0.9783 & 0.9834 & 0.9729 & 0.9382 & 0.9505 & 0.9374 \\
\hline \multirow{4}{*}{$\begin{array}{l}\text { Mean absolute error and standard } \\
\text { deviation for test set ( } 100 \% \text { data })\end{array}$} & RMSE & 0.3318 & 0.3145 & 0.3581 & 0.4984 & 0.4744 & 0.4805 \\
\hline & MAE & 0.2664 & 0.2417 & 0.2843 & 0.4167 & 0.3748 & 0.4150 \\
\hline & S.D. & 0.2048 & 0.2083 & 0.2254 & 0.2856 & 0.3038 & 0.2529 \\
\hline & MAE + 3.S.D. & 0.8808 & 0.8666 & 0.9605 & 1.2735 & 1.2862 & 1.1737 \\
\hline \multirow{4}{*}{$\begin{array}{c}\text { Mean absolute error and standard } \\
\text { deviation for test set (after } \\
\text { removing } 5 \% \text { data with high } \\
\text { residuals) }\end{array}$} & RMSE & 0.2598 & 0.2326 & 0.2878 & 0.4457 & 0.3914 & 0.4285 \\
\hline & MAE & 0.2254 & 0.1981 & 0.2422 & 0.3735 & 0.3172 & 0.3740 \\
\hline & S.D. & 0.1342 & 0.1266 & 0.1613 & 0.2550 & 0.2404 & 0.2194 \\
\hline & MAE + 3·S.D. & 0.6279 & 0.5778 & 0.7261 & 1.1385 & 1.0385 & 1.0322 \\
\hline \multirow{4}{*}{$\begin{array}{l}\text { Distribution of prediction errors } \\
\qquad(\text { in } \%)\end{array}$} & $\omega \mathrm{N}$ in range $0.10 \times \Delta \operatorname{lgk}_{7(\mathrm{TR})}$ & $6.6667^{a}$ & $6.6667^{a}$ & $6.6667^{\mathrm{a}}$ & $25.000^{b}$ & $25.000^{b}$ & $16.667^{b}$ \\
\hline & $\omega \mathrm{N}$ in range $0.15 \times \Delta \operatorname{lgk}_{7}(\mathrm{TR})$ & $0.0000^{\mathrm{a}}$ & $0.0000^{\mathrm{a}}$ & $0.0000^{\mathrm{a}}$ & $0.0000^{b}$ & $8.3333^{b}$ & $0.0000^{b}$ \\
\hline & $\omega \mathrm{N}$ in range $0.20 \times \Delta \operatorname{lgk}_{7}(\mathrm{TR})$ & $0.0000^{\mathrm{a}}$ & $0.0000^{\mathrm{a}}$ & $0.0000^{\mathrm{a}}$ & $0.0000^{\mathrm{b}}$ & $0.0000^{\mathrm{b}}$ & $0.0000^{b}$ \\
\hline & $\omega \mathrm{N}$ in range $0.25 \times \Delta \operatorname{lgk}_{7}(\mathrm{TR})$ & $0.0000^{\mathrm{a}}$ & $0.0000^{\mathrm{a}}$ & $0.0000^{\mathrm{a}}$ & $0.0000^{b}$ & $0.0000^{b}$ & $0.0000^{b}$ \\
\hline Prediction quality & - & \multicolumn{6}{|c|}{ Good } \\
\hline Systematic error presence & - & \multicolumn{6}{|c|}{ Absent } \\
\hline \multicolumn{8}{|c|}{$\begin{array}{l}{ }^{1} \text { Where } \mathrm{R}^{2}, \mathrm{R}^{2} \text {, and } \mathrm{R}^{\prime 2} \text { are determination coefficients calculated with and without taking into account the origin; } \mathrm{R}_{\mathrm{m}}^{2} \text { is the averaged } \\
\text { determination coefficient of the regression function, calculated using values of determination coefficients on the ordinate axis ( } \mathrm{R}^{2} \mathrm{~m} \text { ) and } \\
\text { using them on the abscissa }\left(\mathrm{R}^{\prime 2} \mathrm{~m}\right) \text { respectively; } \Delta \mathrm{R}_{\mathrm{m}}^{2} \text { is the difference between } \mathrm{R}_{\mathrm{m}}^{2} \text { and } \mathrm{R}^{\prime 2} \mathrm{~m} ; \mathrm{Q}^{2} \mathrm{~F} 1 \text { and } \mathrm{Q}^{2} \mathrm{~F} 2 \text {, are determination coefficients } \\
\text { calculated for the compounds of test sets TS1 and TS2 taking into account the average lgk value of the compounds from training and test } \\
\text { sets, respectively; CCC is the concordance correlation coefficient; MAE is the mean absolute error; S.D. is the standard deviation; wN is the } \\
\text { percentage of test sets TS1 and TS2, for which the prediction error is less than the interval proportional to } 0.1,0.15,0.20 \text {, and } 0.25 \text { of } \Delta l g k 7 \text { of } \\
\text { training sets TR2 (a) and TR3 (b). }\end{array}$} \\
\hline
\end{tabular}

Table 6. The lgk 7 values of $N$-2-ethylhexyl- $N^{\prime}$-phenyl- $n$-phenylendiamine (8-PPDA) predicted with the M3, M6 and M9 models.

\begin{tabular}{|c|c|c|c|}
\hline Model & Applicability (AD) & $\begin{array}{l}\text { Predicted Value } \\
\operatorname{lgk}_{7} \text { pred }\end{array}$ & $\begin{array}{c}\text { Predicted value } \mathrm{k}_{7}{ }^{\text {pred }} \cdot 10^{-5} \\
\left(\mathrm{~L} \cdot \mathrm{mol}^{-1} \cdot \mathrm{s}^{-1}\right)\end{array}$ \\
\hline M3 & in $\mathrm{AD}$ & 5.3258 & 2.12 \\
\hline M6 & in $\mathrm{AD}$ & 5.3252 & 2.12 \\
\hline M9 & in $\mathrm{AD}$ & 5.5896 & 3.88 \\
\hline
\end{tabular}


Note that compound 8-PPDA has already used as an antioxidant in composite synthetic rubbers [67]. However, its antioxidant activity using classical model reactions of liquidphase oxidation of ethylbenzene or cumene has not been studied. Thus, we complement our calculations with the corresponding experiments to measure rate constant $\mathrm{k}_{7}$.

We have studied the antioxidant properties of 8-PPDA under the initiated radicalchain oxidation of ethylbenzene in the kinetic mode at $348 \mathrm{~K}$ (azodiisobutyronitrile is the initiator of the oxidative process). The kinetic curves demonstrate that the introduction of 8-PPDA into the reaction system decreases the rate of the oxygen absorption measured in the induction period (Figure 6, Table 7).

Table 7. The dependence of the initial rate of the ethylbenzene oxidation on the 8-PPDA concentration $\left(\mathrm{V}_{\mathrm{i}}=2.4 \cdot 10^{-7} \mathrm{~mol} \cdot \mathrm{L}^{-1} \cdot \mathrm{s}^{-1}, \mathrm{~T}=348 \mathrm{~K}\right)$.

\begin{tabular}{cc}
\hline$[8-P P D A] \cdot \mathbf{1 0}^{\mathbf{4}}(\mathbf{M})$ & $\mathbf{V}_{\mathbf{0}} \cdot \mathbf{1 0}^{\mathbf{6}}\left(\mathbf{m o l} \cdot \mathbf{L}^{-\mathbf{1}} \cdot \mathbf{s}^{-\mathbf{1}}\right)$ \\
\hline 0.000 & 4.700 \\
\hline 0.200 & 2.480 \\
\hline 0.403 & 0.801 \\
\hline 0.805 & 0.481 \\
\hline 1.610 & 0.191 \\
\hline
\end{tabular}

As follows from Figure 7, the inhibition parameter $\mathrm{F}$ deduced from the initial rates of the inhibited oxidation linearly depends on the 8-PPDA concentration in the range of its concentrations $(0.2-1.61) \cdot 10^{-4} \mathrm{~mol} \cdot \mathrm{L}^{-1}$ :

$$
\mathrm{F}=\frac{\mathrm{V}_{0}}{\mathrm{~V}}-\frac{\mathrm{V}}{\mathrm{V}_{0}}=\frac{\mathrm{fk}_{7}[\mathrm{InH}]}{\sqrt{2 \mathrm{k}_{6} \mathrm{~V}_{\mathrm{i}}}}
$$

where $\mathrm{V}$ and $\mathrm{V}_{0}$ are the rates of the oxygen absorption with and without 8-PPDA in the reaction system, respectively.

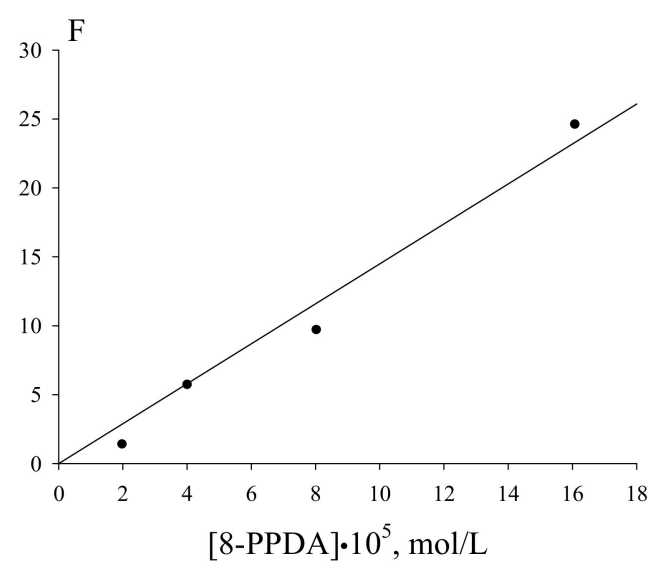

Figure 7. Dependence of the inhibition parameter on the 8-PPDA concentrations $\left(\mathrm{V}_{\mathrm{i}}=2.4 \cdot 10^{-7}\right.$ $\left.\mathrm{mol} \cdot \mathrm{L}^{-1} \cdot \mathrm{s}^{-1}, 348 \mathrm{~K}\right)$; the correlation coefficient $\mathrm{R}=0.95$.

The linearization in the coordinates of Equation (7) lead to the effective rate constant

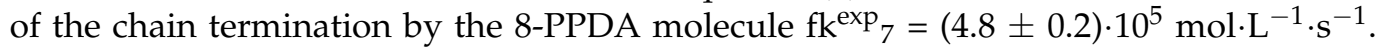
The induction period $(\tau)$ on the oxygen absorption curves corresponding the 8-PPDAinhibited ethylbenzene oxidation (Figure 6) linearly depends on the inhibitor concentration. This dependence (Figure 8) allows assessing the stoichiometric inhibition coefficient via Equation (8):

$$
\tau=\frac{\mathrm{f}[\operatorname{InH}]}{\mathrm{V}_{\mathrm{i}}}
$$


where $\tau$ is the induction period on the kinetic curves of oxygen absorption upon the oxidation of ethylbenzene inhibited by 8-PPDA and $V_{i}$ is the initiation rate of the oxidation process. The calculation according to Equation (8) gives $\mathrm{f}=2$. Thus, the inhibition rate constant $\mathrm{k}_{7}{ }^{\exp }$ for 8-PPDA can be calculated as:

$$
\mathrm{k}_{7}^{\exp }=\mathrm{fk}_{7}^{\exp } / \mathrm{f}
$$

where $\mathrm{f}$ is the antioxidant capacity that equals the number of radical intermediates cease to exist in the interaction with one antioxidant molecule.

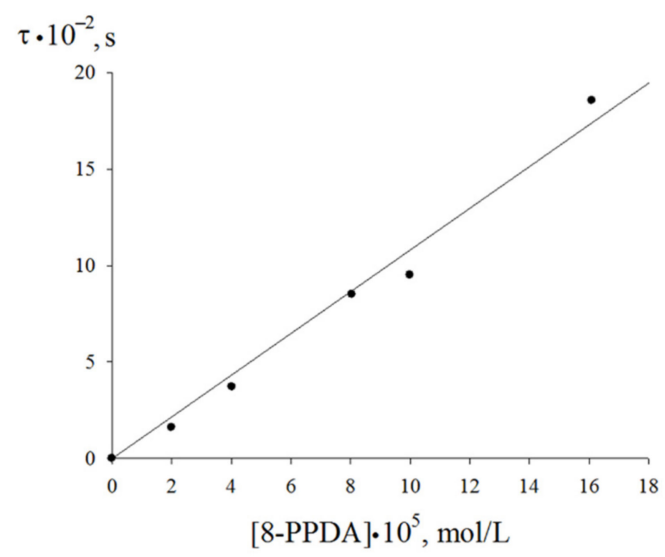

Figure 8. Dependence of the induction period on the initial concentration of the inhibitor ( $348 \mathrm{~K}$, $\mathrm{V}_{\mathrm{i}}=2.4 \cdot 10^{-7} \mathrm{~mol} \cdot \mathrm{L}^{-1} \cdot \mathrm{s}^{-1}$ ).

A comparative analysis of the predicted values $\left(\operatorname{lgk}_{7}{ }^{\text {pred }}\right)$ with the experimental one $\left(\operatorname{lgk}_{7}{ }^{\mathrm{obs}}\right)$ demonstrates a high predictability of the QSAR consensus models M3, M6 and M9. Hence, they can be applied to screening novel antioxidant structures.

Thus, all QSAR consensus models M1-M9 have descriptive and predictive ability as follows from the comparison of experimental and predicted $\operatorname{lgk}_{7}$ values for the TR1-TR3 structures, external and internal TS1 and TS2 test sets, and 8-PPDA. These models can be used for screening on virtual libraries and databases to find new antioxidants among substituted phenols, polyphenols, aminophenols, aromatic amines and uracils.

Thus, the approach implemented in the GUSAR 2013 program have been previously used only for modeling the biological activity of low-molecular compounds. We have shown that it allows simulating the key kinetic parameter of antioxidant activity $\left(\mathrm{k}_{7}\right)$ with high accuracy and this program could be recommended as an auxiliary tool when searching for new antioxidants.

\section{Conclusions}

Based on the QSAR methodology implemented in the GUSAR 2013 program, we have studied a quantitative structure-antioxidant activity relationship in the set of 74 organic compounds (phenol, aminophenols, aromatic amines and uracil derivatives; see structural formulas I-V), which have a different degree of antioxidant activity expressed through the $\operatorname{lgk}_{7}$ parameter $\left(\operatorname{lgk}_{7} 0.01 \div 6.65\right.$ for these compounds). Operating with MNA/QNA descriptors, descriptors corresponding to the whole molecule (topological length, topological volume and lipophilicity), RBF-SCR method, we have developed 9 statistically significant QSAR consensus models. The QSAR models demonstrate high accuracy in predicting the $\operatorname{lgk}_{7}$ values for the compounds of training sets and appropriately predict $l g k_{7}$ for the test sets $\left(\mathrm{R}^{2} \mathrm{TR}>0.6 ; \mathrm{Q}^{2} \mathrm{TR}>0.5 ; \mathrm{R}^{2} \mathrm{TS}>0.5\right)$. We recommend using the QSAR models M3, M6 and M9 for virtual screening of new antioxidants because they are based on a combination of the descriptors different types. This guarantees reliability of the predicted lgk 7 values.

However, it should be borne in mind that the QSAR consensus models we have developed are not universal. These models are able to adequately predict the numerical 
values of the $\operatorname{lgk}_{7}$ parameter only for antioxidants with general structural formulas I-V. At the same time, the range of correct prediction of the $\operatorname{lgk}_{7}$ parameter using all the QSAR models developed by us, including the M3, M6, M9 models, is quite wide. The experimental values of the $\lg k_{7}$ parameter for the modeled antioxidants, on the basis of which all QSAR models were developed and their validity was assessed, varied from 0.01 to 6.65 .

In general, the results of the structural analysis using the GUSAR 2013 program are fully consistent with the literature data on the effect of various ortho, meta, and para substituents on the antioxidant activity of phenols. The introduction of electron-donor substituents into the ortho, meta, and para positions of compounds I-IV increases the $\operatorname{lgk}_{7}$ parameter. Electron-acceptor substituents in the same positions reduce the antioxidant activity of phenols. In uracils with the general structural formulas $V$, the effect of electrondonor substituents is ambiguous. The introduction of methyl groups in the positions $R_{1}$, $R_{2}, R_{4}$ increases the nominal value of the parameter lgk but replacing the hydrogen atom from $R_{3}$ by the hydroxyl or amino group, in contrast, leads to a decrease in the antioxidant properties (see Supplementary Materials, Figures S1-S6).

A good agreement of the predicted and experimental $\operatorname{lgk}_{7}$ values for the compounds of the test sets and 8-PPDA, a "young" member of the inhibitors family, indicates that the GUSAR 2013 algorithms are applicable to simulating the kinetic parameters of the model liquid-phase oxidation reactions of organic hydrocarbons. Thus, the GUSAR 2013 program allows modeling kinetic parameters relating to non-specific activity in addition to the ADMET properties and diverse biological activities mentioned in the introduction. Previously, we have reported the first results of a successful QSPR simulation of nonspecific activity using the GUSAR 2013 program. In the previous study [68], we have demonstrated the efficiency of the GUSAR descriptors for simulating the photovoltaic performances of the methanofullerene derivatives (we built six statistically significant QSPR consensus models for predicting the power conversion efficiencies of the methanofullerene-based organic solar cells). This QSPR study develops the idea of successfully applying the GUSAR approaches to describing nonspecific activities of the compounds. Our studies in this area will be continued.

In summary, the approach used in the GUSAR 2013 program for constructing regression models demonstrates high performance as applied to both small and large data sets including the antioxidants with different structures. As the program implements a twodimensional approach, there is no need to search through the entire conformational space and select the most bioactive conformation of the modeled compounds. The mentioned issues open the opportunity for the application of GUSAR 2013 to the antioxidant studies.

This work was supported by grant No. 19-73-20073 of the Russian Science Foundation.

Supplementary Materials: Supplementary file contains Figures S1-S10 and Tables S1-S9.

Author Contributions: Conceptualization, V.K. and I.S.; methodology, V.K.; software, Y.M.; validation, V.K., I.S. and A.G.; formal analysis, G.S.; investigation, V.K.; resources, V.K.; data curation, V.K.; writing - original draft preparation, V.K. and Y.M.; writing-review and editing, A.G. and I.S.; visualization, G.S.; supervision, V.K.; project administration, A.G.; funding acquisition, V.K. All authors have read and agreed to the published version of the manuscript.

Funding: This research was funded by Russian Science Foundation, grant number 19-73-20073.

Data Availability Statement: The structures of the compounds presented in this study are available upon request from the respective author.

Conflicts of Interest: The authors declare that they have no conflict of interest.

\section{References}

1. Kirschweng, B.; Tátraaljai, D.; Földes, E.; Pukanszky, B. Natural antioxidants as stabilizers for polymers. J. Polym. Degrad. Stab. 2017, 145, 25-40. [CrossRef]

2. Aguilar, G.; Mazzamaro, G.; Rasberger, M. Oxidative Degradation and Stabilisation of Mineral Oil-Based Lubricants. In Chemistry and Technology of Lubricants, 3rd ed.; Mortier, R.M., Fox, M., Orszulik, S.T., Eds.; Springer: Dordrecht, The Netherlands, 2010; pp. 107-152. [CrossRef] 
3. Rasberger, M. Oxidative degradation and stabilisation of mineral oil based lubricants. In Chemistry and Technology of Lubricants; Mortier, R.M., Orszulik, S.T., Eds.; Springer: Dordrecht, The Netherlands, 1997; pp. 98-143. [CrossRef]

4. Hamblin, P. Oxidative stabilisation of synthetic fluids and vegetable oils. J. Synth. Lubr. 1999, 16, 157-181. [CrossRef]

5. Denisov, E.T.; Denisova, T.G. The reactivity of natural phenols. Russ. Chem. Rev. 2009, 78, 1147-1173. [CrossRef]

6. Akers, M.J. Drug stabilization against oxidative degradation. J. Chem. Educ. 1985, 62, 325-327. [CrossRef]

7. Celestino, M.T.; Magalhães, U.D.O.; Fraga, A.G.M.; Carmo, F.A.D.; Lione, V.; Castro, H.C.; Sousa, V.P.d.; Rodrigues, C.R.; Cabral, L.M. Rational use of antioxidants in solid oral pharmaceutical preparations. J. Pharm. Sci. 2012, 48, 405-415. [CrossRef]

8. Chakrabarti, P.K.; Harindran, J.; Saraf, P.G.; Wamburkar, M.N.; Naik, S.R. Role of new Antioxidants in the Stabilization of Ophthalmic and ear Dosage form Preparation of Hamycin. J. Drug Dev. Ind. Pharm. 1993, 19, 2595-2609. [CrossRef]

9. Russo, G.L.; Tedesco, I.; Spagnuolo, C.; Russo, M. Antioxidant polyphenols in cancer treatment: Friend, foe or foil? Semin. Cancer Biol. 2017, 46, 1-13. [CrossRef]

10. Servili, M.; Sordini, B.; Esposto, S.; Urbani, S.; Veneziani, G.; Di Maio, I.; Selvaggini, R.; Taticchi, A. Biological Activities of Phenolic Compounds of Extra Virgin Olive Oil. J. Antiox. 2014, 3, 1-23. [CrossRef]

11. Fuchs-Tarlovsky, V. Role of antioxidants in cancer therapy. J. Nutr. 2013, 29, 15-21. [CrossRef]

12. White, P.; Oliveira, R.; Oliveira, A.; Serafini, M.; Araújo, A.; Gelain, D.; Moreira, J.; Almeida, J.; Quintans, J.; Quintans-Junior, L.; et al. Antioxidant Activity and Mechanisms of Action of Natural Compounds Isolated from Lichens: A Systematic Review. J. Mol. 2014, 19, 14496-14527. [CrossRef]

13. Kahl, R.; Hildebrandt, A.G. Methodology for studying antioxidant activity and mechanisms of action of antioxidants. J. Food Chem. Toxic. 1986, 24, 1007-1014. [CrossRef]

14. Denisov, E.T.; Afanas'ev, I.B. (Eds.) Oxidation and Antioxidants in Organic Chemstry and Biology. In Chemisrty/Organic Chemistry; CRC Press: Boca Raton, FL, USA, 2005; p. 992.

15. Alam, M.N.; Bristi, N.J.; Rafiquzzaman, M. Review on in vivo and in vitro methods evaluation of antioxidant activity. Saudi Pharm. J. 2013, 21, 143-152. [CrossRef] [PubMed]

16. Anthony, K.; Saleh, M. Free Radical Scavenging and Antioxidant Activities of Silymarin Components. J. Antiox. 2013, 2, 398-407. [CrossRef] [PubMed]

17. Nimse, S.B.; Pal, D. Free radicals, natural antioxidants, and their reaction mechanisms. J. RSC Adv. 2015, 5, $27986-28006$. [CrossRef]

18. Apak, R.; Özyürek, M.; Guclu, K.; Capanoglu, E. Antioxidant Activity/Capacity Measurement. 1. Classification, Physicochemical Principles, Mechanisms, and Electron Transfer (ET)-Based Assays. J. Agric. Food. Chem. 2016, 64, 997-1027. [CrossRef] [PubMed]

19. Pisoschi, A.M.; Negulescu, G.P. Methods for Total Antioxidant Activity Determination. Biochem. Anal. Biochem. 2015, 1, 1-10. [CrossRef]

20. Prior, R.L.; Wu, X.; Schaich, K. Standardized Methods for the Determination of Antioxidant Capacity and Phenolics in Foods and Dietary Supplements. J. Agric. Food. Chem. 2005, 53, 4290-4302. [CrossRef]

21. Khajehnasiri, F.; Mortazavi, S.B.; Allameh, A.; Akhondzadeh, S.; Hashemi, H. Total antioxidant capacity and malondialdehyde in depressive rotational shift workers. J Environ. Public. Health. 2013, 2013, 150693. [CrossRef]

22. Aliahmat, N.S.; Noor, M.R.; Yusof, W.J.; Makpol, S.; Ngah, W.Z.; Yusof, Y.A. Antioxidant enzyme activity and malondialdehyde levels can be modulated by Piper betle, tocotrienol rich fraction and Chlorella vulgaris in aging C57BL/6 mice. J. Clin. 2012, 67, 1447-1454. [CrossRef]

23. Heim, K.E.; Tagliaferro, A.R.; Bobilya, D.J. Flavonoid antioxidants: Chemistry, metabolism and structure-activity relationships. J. Nutr. Biochem. 2002, 13, 572-584. [CrossRef]

24. Cao, G.; Sofic, E.; Prior, R.L. Antioxidant and prooxidant behavior of flavonoids: Structure-activity relationships. J. Free Radic. Biol. Med. 1997, 22, 749-760. [CrossRef]

25. Dugas, A.J.; Castañeda-Acosta, J.; Bonin, G.C.; Price, K.L.; Fischer, N.H.; Winston, G.W. Evaluation of the Total Peroxyl RadicalScavenging Capacity of Flavonoids: Structure-Activity Relationships. J. Nat. Prod. 2000, 63, 327-331. [CrossRef] [PubMed]

26. Kumar, S.; Pandey, A.K. Chemistry and Biological Activities of Flavonoids: An Overview. Sci. World J. 2013, 162750. [CrossRef] [PubMed]

27. Denisov, E.T.; Denisova, T.G. (Eds.) Handbook of Antioxidants: Bond Dissociation Energies, Rate Constants, Activation Energies, and Enthalpies of Reactions. In Chemisrty/Thermodynamics; CRC Press: Boca Raton, FL, USA, 1999; p. 312.

28. Al-Sehemi, A.G.; Irfan, A. Effect of donor and acceptor groups on radical scavenging activity of phenol by density functional theory. Arab. J. Chem. 2017, 10, 1703-1710. [CrossRef]

29. Kajiyama, T.; Ohkatsu, Y. Effect of para-substituents of phenolic antioxidants. J. Polym. Degrad. Stab. 2001, 71, 445-452. [CrossRef]

30. Cheng, Z.; Ren, J.; Li, Y.; Chang, W.; Chen, Z. Phenolic antioxidants: Electrochemical behavior and the mechanistic elements underlying their anodic oxidation reaction. Redox Rep. 2002, 7, 395-402. [CrossRef]

31. Vedernikova, I.; Tollenaere, J.P.; Haemers, A. Quantum mechanical evaluation of the anodic oxidation of phenolic compounds. JPOC 1999, 12, 144-150. [CrossRef]

32. Anouar, E. A Quantum Chemical and Statistical Study of Phenolic Schiff Bases with Antioxidant Activity against DPPH Free Radical. J. Antiox. 2014, 3, 309-322. [CrossRef]

33. Lakkadi, A.; Vuppala, S.; Tigulla, P. Novel in vitro antioxidant estimation of phenolic compounds and molecular modeling studies. Int. Res. J. Pharm. 2013, 2, 148-152. [CrossRef] 
34. Hoelz, L.V.B.; Horta, B.A.C.; Araújo, J.Q.; Albuquerque, M.G.; Alencastro, R.B.d.; da Silva, J.F.M. Quantitative structure-activity relationships of antioxidant phenolic compounds. J. Chem. Pharm. Res. 2010, 2, 291-306.

35. Khairullina, V.R.; Gerchikov, A.J.; Lagunin, A.A.; Zarudii, F.S. QSAR Modelling of Thymidylate Synthase Inhibitors in a Series of Quinazoline Derivatives. Pharm. Chem. J. 2018, 51, 884-888. [CrossRef]

36. Khairullina, V.R.; Gimadieva, A.R.; Gerchikov, A.Y.; Mustafin, A.G.; Zaarudii, F.S. Quantitative structure-activity relationship of the thymidylate synthase inhibitors of Mus musculus in the series of quinazolin-4-one and quinazolin-4-imine derivatives. J. Mol. Graph. Modell. 2018, 85, 198-211. [CrossRef] [PubMed]

37. Zakharov, A.V.; Lagunin, A.A.; Filimonov, D.A.; Poroikov, V.V. Quantitative prediction of antitarget interaction profiles for chemical compounds. J. Chem. Res. Toxicol. 2012, 25, 2378-2385. [CrossRef] [PubMed]

38. Taipov, I.A.; Khayrullina, V.R.; Khoma, V.K.; Gerchikov, A.J.; Zarudiy, F.S.; Bege, K. Virtual screening in the row of effective inhibitor of catalytic activity-A4-hydrolase. J. Vestn. Bashkir. Univ. 2012, 17, 886-891.

39. Zakharov, A.V.; Peach, M.L.; Sitzmann, M.; Nicklaus, M.C. A New Approach to Radial basis function approximation and Its application to QSAR. J. Chem. Inf. Model. 2014, 54, 713-719. [CrossRef] [PubMed]

40. Lagunin, A.A.; Geronikaki, A.; Eleftheriou, P.; Pogodin, P.V. Rational Use of Heterogeneous Data in Quantitative StructureActivity Relationship (QSAR) Modeling of Cyclooxygenase/Lipoxygenase Inhibitors. J. Chem. Inf. Model. 2019, 59, 713-730. [CrossRef] [PubMed]

41. Lagunin, A.A.; Romanova, M.A.; Zadorozhny, A.D.; Kurilenko, N.S.; Shilov, B.V.; Pogodin, P.V.; Ivanov, S.M.; Filimonov, D.A.; Poroikov, V.V. Comparison of Quantitative and Qualitative (Q)SAR Models Created for the Prediction of Ki and IC50 Values of Antitarget Ingibitors. J. Front. Pharmacol. 2018, 9, 1136. [CrossRef]

42. Khayrullina, V.R.; Gerchikov, A.Y.; Lagunin, A.A.; Zarudii, F.S. Quantitative Analysis of Structure-Activity Relationships of Tetrahydro-2H-isoindole Cyclooxygenase-2 Inhibitors. J. Biokhimiya 2015, 80, 74-86. [CrossRef]

43. Khairullina, V.R.; Akbasheva, Y.Z.; Gimadieva, A.R.; Mustafin, A.G. Analysis of the relationship «structure-activity» in theseries of certain 5-ethyluridine derivatives with pronounced anti-herpetic activity. J. Vestnik Bashk. Univ. 2017, 22, 960-965.

44. Martynova, Y.Z.; Khairullina, V.R.; Nasretdinova, R.N.; Garifullina, G.G.; Mitsukova, D.S.; Gerchikov, A.Y.; Mustafin, A.G. Determination of the chain termination rate constants of the radical chain oxidation of organic compounds on antioxidant molecules by the QSPR method. J. Russ. Chem. Bull. 2019, 69, 1679-1691. [CrossRef]

45. Filimonov, D.A.; Zakharov, A.V.; Lagunin, A.A.; Poroikov, V.V. QNA based "Star Track" QSAR approach. SAR QSAR Environ. J. Resolut. 2009, 20, 679-709. [CrossRef] [PubMed]

46. Lagunin, A.; Zakharov, A.; Filimonov, D.; Poroikov, V. QSAR Modelling of Rat Acute Toxicity on the Basis of PASS Prediction. J. Mol. Inf. 2011, 30, 241-250. [CrossRef]

47. Roy, K.; Mitra, I.; Kar, S.; Ojha, P.K.; Das, R.N.; Kabir, H. Comparative Studies on Some Metrics for External Validation of QSPR Models. J. Chem. Inf. Model. 2012, 52, 396-408. [CrossRef] [PubMed]

48. Denisov, E.T. Konstanty Skorosti Gomoliticheskih Zhidkofaznyh Reakcij; Nauka: Moscow, Russia, 1971; p. 711.

49. Emanuehl, N.M.; Denisov, E.T.; Majzus, Z.K. Liquid-Phase Oxidation of Hidrocarbons; Plenum Press: New York, NY, USA, 1967; p. 350 .

50. Chihara, H.; Nakamura, N.; Hellwege, K.H.; Hellwege, A.M. Numerical Data and Functional Relationships in Science and Technology: New Series. In Landolt-Boernstein; Chihara, H., Nakamura, N., Hellwege, K.H., Hellwege, A.M., Eds.; Springer: Berlin, Germany, 1993; Volume 13, pp. 1984-1985.

51. MarvinSketch. Available online: https:// chemaxon.com/download/marvin-suite (accessed on 14 December 2020).

52. DiscoveryStudioVisualiser. Available online: https://www.3ds.com (accessed on 14 December 2020).

53. Dearden, J.C.; Cronin, M.T.D.; Kaiser, K.L.E. How not to develop a quantitative structure-activity or structure-property relationship (QSAR/QSPR). J. SAR QSAR Environ. Res. 2009, 20, 241-266. [CrossRef] [PubMed]

54. Alov, P.; Tsakovska, I.; Pajeva, I. Computational Studies of Free Radical-Scavenging Properties of Phenolic Compounds. Curr. Top. Med. Chem. 2015, 15, 85-104. [CrossRef] [PubMed]

55. Gramatica, P.; Sangion, A. A Historical Excursus on the Statistical Validation Parameters for QSAR Models: A Clarification Concerning Metrics and Terminology. J. Chem. Inform. Model. 2016, 56, 1127-1131. [CrossRef]

56. Consonni, V.; Ballabio, D.; Todeschini, R. Evaluation of model predictive ability by external validation techniques. J. Chemom. 2010, 24, 194-201. [CrossRef]

57. Chirico, N.; Gramatica, P. Real External Predictivity of QSAR Models: How to Evaluate It? Comparisonof Different Validation Criteria and Proposal of Using the Concordance Correlation Coefficient. J. Chem. Inform. Model. 2011, 51, 2320-2335. [CrossRef]

58. Roy, P.P.; Paul, S.; Mitra, I.; Roy, K. On Two Novel Parameters for Validation of Predictive QSAR Models. Molecules 2009, 14, 1660-1701. [CrossRef]

59. Roy, K.; Das, R.N.; Ambure, P.; Aher, R.B. Be aware of error measures. Further studies on validation of predictive QSAR models. J. Chemom. Intell. Lab. Syst. 2016, 152, 18-33. [CrossRef]

60. Xternal Validation Plus. Available online: https://sites.google.com/site/dtclabxvplus (accessed on 14 December 2020).

61. Roginskij, V.A. Fenol'nye antioksidanty: Reaktsionnaya sposobnost' i effektionost' In Institut Himicheskoj Fiziki AN SSSR; Nauka: Moscow, Russia, 1988; p. 246.

62. Roginsky, V.; Lissi, E.A. Review of methods to determine chainbreaking antioxidant activity in food. J. Food Chem. 2005, 92, 235-254. [CrossRef] 
63. Khairullina, V.R.; Gerchikov, A.Y.; Urazaeva, Y.R.; Savchenko, R.G.; Odinokov, V.N. Antioxidant Properties of Conjugates of 20-Hydroxyecdysone Derivatives with a Polysubstituted Chromanylaldehyde. J. Kinet. Catal. 2010, 51, 502-506. [CrossRef]

64. Khairullina, V.R.; Gerchikov, A.Y.; Safarova, A.B.; Khalitova, R.R.; Spivak, A.Y.; Shakurova, E.R.; Odinokov, V.N. Antioxidant Properties of Conjugates of Triterpenic Acids with Amido Derivatives of Trolox. J. Kinet. Catal. 2011, 52, 186-191. [CrossRef]

65. Khayrullina, V.R.; Gerchikov, A.J.; Ilina, E.A.; Drevko, J.B.; Isaeva, A.Y.; Drevko, B.I. Antioxidant properties of some 7,8-benzo-5,6dihydro(4H)selenochromene derivaties. J. Kinet. Catal. 2013, 54, 14-17. [CrossRef]

66. Koltsov, N.I.; Ushmarin, N.F.; Petrov, A.E.; Petrov, N.P.; Petrov, N.N.; Verhunov, S.M. Research of influence of technological additives on properties of rubbers on the basis of BNR new generation. Part 3. Novantox 8 PFDA. J. Butlerov Commun. 2010, 21, 22-28.

67. Martynova, Y.Z.; Khairullina, V.R.; Gimadieva, A.R.; Mustafin, A.G. QSAR-Modeling of desoxyuridine triphosphatase inhibitors in a series of some derivatives of uracil. J. Biomed. Chem. 2019, 65, 103-113. [CrossRef]

68. Martynova, Y.Z.; Khairullina, V.R.; Biglova, Y.N.; Mustafin, A.G. Quantitative structure-property relationship modeling of the C60 fullerene derivatives as electron acceptors of polymer solar cells: Elucidating the functional groups critical for device performance. J. Mol. Graph. Model. 2019, 88, 49-61. [CrossRef] 